\title{
Disentangling the Antecedents of Relationship between Deep Approach to Learning and Student Learning Outcomes
}

\author{
Michael Yao-Ping Peng ${ }^{1, *}$ and Sheng-Hwa Tuan ${ }^{2}$ \\ ${ }^{1}$ No.99, Denglong Rd., Mawei District, Fuzhou, China \\ ${ }^{2}$ No.48, Hsuan Chuang Rd., Hsinchu City, Taiwan \\ *Corresponding author
}

\begin{abstract}
The multiple characteristics of students encourage universities to provide a learning environment that integrates teaching and learning in one and to strengthen students' learning motivation through student-oriented teaching model, so as to enhance students' input in study. In this study, the concept of depth learning is adopted to measure students' input in study, so as to explore the outcomes of specialized teaching mode and students' learning outcomes. Therefore, this study aimed to analyze a sample of 2,342 students from 16 Taiwanese higher education institutions by structural equation modeling. The results showed that specialized teaching modes (explorative and exploitative learning) could increase deep approach to learning; explorative and exploitative learning have positive effects on learning outcomes (cognitive gains and non-cognitive gains); deep approach to learning has significant mediated effect between teaching modes and learning outcomes.
\end{abstract}

Keywords-exploitative learning; explorative learning; deep approach to learning; student learning outcomes

\section{INTRODUCTION}

With high-quality standards, planning courses and teaching, reviewing learning achievement and bringing up talented people who combine learning and using in the workplace, replacing the past as the development direction of mass production graduates. Recent studies in higher education have pointed out that student learning outcomes can be significantly improved through the improvement of teaching quality, curriculum design innovation, and optimization of resource equipment (Maringe and Sing 2014; Pike et al. 2011, 2012).

Studies show that higher education institutions have the greatest impact on students' learning and experience and perception of students throughout the learning process, including teachers' teaching quality, teacher-student relationship interaction, students' academic performance, and participation in the college's internal and external activities (Pike et al., 2012), making it a powerful social influence (Snyder 1971; Weidman 1979, 1989). The most important thing is to stimulate students' initiative in participating in their own activities and to obtain various learning experiences after investing in them. Since most of the factors affecting student learning outcomes are indirect factors (Terenzini and Pascarella 1991; Pascarella and Terenzini 2005), it is necessary to verify the nature of these indirect effects (Terenzini and Pascarella 1991).

Smart et al. (2000) regards students' learning engagement as an important mediated variable and verifies the relationship between academic development and learning outcomes. Scholars believe that learning input means learning behaviors that students engage in college and their appropriateness for the experience of higher education institutions and disciplines (Kuh et al. 2006). Skills such as problem-solving, communication, and interpersonal (Choi and Rhee 2014) play an important role in the learning process. Deep approach to learning is the preferred learning engagement for most students. Students who use deep approach to learning will be able to process, retain, integrate, and transfer important information more quickly than students with surface approaches to learning (Prosser and Millar, 1989; Ramsden, 2003). In summary, this study will disentangle the antecedents of relationship between deep approach to learning and student learning outcomes, and explore it with a more complete research framework.

\section{LITERATURE REVIEW}

\section{A. Explorative and Exploitative Teaching Modes}

In the study of student learning, scholars build a new and richer understanding and discussion based on a large amount of known knowledge, especially through the observation of other people's behavior. The learner begins to try to complete the knowledge base required for a specific task (Oleson \& Hora, 2014). Therefore, to develop students' learning goals, we must increase their participation in learning activities so that they can use their full learning potential. In the process of inspiring students to learn and engage, teachers should transform from teacher-centered and passive teaching methods to learner-centered and active activities. It also promised to bring students' learning to a deeper level of understanding and to enable students to apply the real paradigms they learned in different situations (Tagg, 2003). Before the students enter the workplace, they should learn to gain the knowledge and skills they need for employment (Corbett, 2005; Unruh, Lachman, \& Pawlina, 2008). Therefore, according to the duality classification, this study divides the learning model into 
"explorative learning" and "exploitative-based learning" from the perspectives of theory and practice.

Explorative learning means that students engage in professional knowledge theory exploration and experiments through participate in investigations (Hmelo-Silver et al., 2007), and study the reasoning knowledge of professional disciplines and analytical skills applied to practice (Philip et al., 2008). Exploitative learning is similar to experience-learning and problem-based learning, emphasizing conscious sensory cognitive processes, learners transform experience into personal knowledge through the interaction of individuals and the environment, conflict, and problem solving (Kolb, 1984). The effects of prior knowledge systems on shaping cognition, behavior and identity have been widely recognized in cognitive psychology and educational research, and there are many groundbreaking studies that also focus on learning and development (Hummel and Randler 2012; Tella 2007; White et al. 2008). These knowledge learning activities may be shaped by the influence of tutors, immediate family members, knowledge of learning methods and subject matter, and practical knowledge in the classroom (Pike et al. 2012).

Therefore, the basic goal of developing student learning is to increase students' engagement in learning activities and to use the full learning potential of students, not just through traditional teaching modes. According to the claims of Schaufeli and Salanova (2007), even in a difficult environment, students can have a high degree of energy and mental resilience, willingness and persistence to complete academic work (vigor); strongly participate in learning assignments and recognize perceptions (dedication) such as significance, enthusiasm, inspiration and challenges; as well as being completely absorbed and happily obsessed with your own work (absorption). In short, the student learning related research indicates that students can study in the educational context, and teachers can design specific and feasible courses and implementation plans through teaching content, teaching methods, attitude development and teacher-student interaction (Corbett, 2005; Hmelo-Silver et al., 2007). Therefore, the classification of learning patterns in this study is an educational situation based on the exploitative of theoretical knowledge exploration and practical experience exploitative, to explore the relationship between learning patterns and learning outcomes, the results should help schools and their teachers understand the optimal curriculum planning and activities.

H1: There is a positive correlation between exploitative learning and deep approach to learning.

$\mathrm{H} 2$ : There is a positive correlation between explorative learning and deep approach to learning.

H3: Exploitative learning has a positive correlation with student learning outcomes.

H4: Explorative learning has a positive correlation with student learning outcomes.

\section{B. Deep Approach to Learn}

In related research on student input, Campbell and Cabrera (2014) proposed that an important measurement tool for measuring student input is the National Survey of Student Engagement (NSSE), which that more than 1,400 institutions have been used to understand effective internal education practices. There are several important measurement variables in this survey tool, such as the measurement construct of deep approach to learning, which is used to measure the internal validity and construct validity of the variable, and to test whether the variable can effectively predict the student's GPA.

Students with deep approach to learning not only focus on the substance, but also emphasize the fundamental meaning of information, interconnection, integration of knowledge and metacognition (Biggs and Tang, 2011; Pascarella et al., 2013;), the development process is the cooperation of students, colleges, universities and teachers, to develop in-depth and concrete teaching models, such as eliciting positive student responses, building student background knowledge, and teaching more interconnectedness between ideas and ideas (Biggs and Tang, 2011; Campbell and Cabrera, 2014). Scholars agree that deep approach to learn is reflected in the use of different learning strategies by students' personal commitment to understanding teaching materials and information, such as extensive reading, integration of different resources, joint discussion of ideas, commitment to linking independent pieces of information to vast constructs or models, and applying knowledge to real-world situations (Biggs 2003; Ramsden, 2003; Tagg, 2003).

From the previous literatures, there are found that the use of deep approach to learning methods will be better than the surface learning, but only the comparison between the two learning methods, whether deep approach to learning can effectively improve students' learning outcomes has been the focus of scholars' efforts in recent years. The study mentions that in engineering, the relevance of deep approach to learn and student outcomes may be weak or inconspicuous; however, some scholars believe that there is still a positive relationship between the two (Greene et al. 2004; Reason et al. 2010), such as academic achievement. The results of the study found that there was a positive relationship between deep approach to learn and results, and a negative relationship between surface learning. This also reflected the students' education system with a well-developed assessment mechanism, they tend to adopt a deep approach to learning strategy to gain more explicit feedback and outcomes. It helps them to understand and internalize new information and improve their knowledge, skills and capabilities (Oleson and Hora 2014). In addition, clear and systematic course guidance will enable students to focus not only on the acquisition of knowledge or facts, but also on the promotion of substantive learning and understanding of their underlying meaning (Laird et al. 2006), all contributing to the improvement of students' critical thinking skills and cognitive needs (Pascarella et al. 2013). In summary, this study proposes the following assumptions:

H5: Deep approach to learning has a positive relationship with student learning outcomes.

Based on the above inference, the research structure proposed in this study is shown in Figure 1 below: 


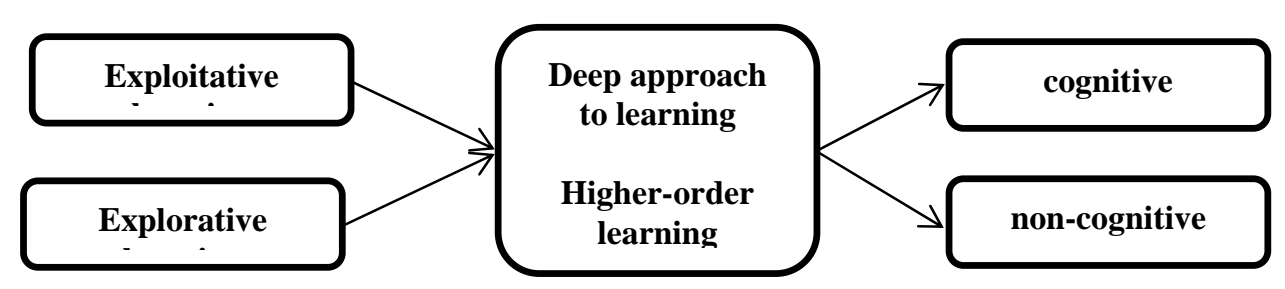

FIGURE I. RESEARCH FRAMEWORK

\section{Methodology}

\section{Sampling}

This study explores the factors affecting students' learning outcomes by self-determination theory, and examines the relationship between learning motivation-input-results to understand the direction and connotation of higher education institutions to improve students' learning outcomes. Higher education institutions that receive subsidies mean that the scale and direction of their teaching models and school affairs development have been recognized by relevant professional scholars and government agencies, and they are appropriately representative when discussing research topics of student learning outcomes. A total of 2,354 students were invited to complete the questionnaire, after deducting 14 invalid questionnaires, 2,340 valid samples were analyzed.

\section{Measures}

This study divides the learning style into two types: "explorative-based learning" and "exploitative learning" through duality. The explorative learning is based on the explorative learning scale proposed by Philip et al. (2008). In order to increase the generality of the scale, the study consolidated 10 items from the primary scale into 8 items. The exploitative-based learning adopts the scale proposed by Li et al. (2007), including career preparation, time management, personal input, and satisfaction. There are 10 items in total.

The deep approach to learn is evaluated by three scales developed by Campbell and Cabrera (2014), Nelson Laird et al. (2006, 2008), and Pascarella et al. (2013). Based on the NSSE items completed in the student sample, it includes high-order learning, integrated learning, and reflective learning. According to the definition and operation of Nelson Laird et al. (2006, 2008) and Pascarella et al. (2013), higher-order learning is measured by four items; integrated learning consists of 5 items; reflective learning includes 2 items.

The outcomes of student learning can be divided into two levels. One is cognitive gains, the other is non-cognitive gains. This study used the scale proposed by Pike et al. (2011). All items mentioned above use the Likert 7-point scale $(1=$ totally disagree; 7 = totally agree).

\section{ANALYSIS RESULTS}

\section{A. Reliability and Validity}

In this study, confirmatory factor analysis (CFA) was used to test the combination reliability, convergence validity, and discriminant validity of facets. All scales used in this study were found to be reliable, with Cronbach's $\alpha$ above .70 in Table 1 . In order to gauge validity, this study employed confirmatory factor analysis (CFA) to verify the construct validity (both convergent and discriminant) of the scales. Hair et al. (2006) recommended convergent validity criteria as follows: (1) standardized factor loading of higher than 0.7 ; (2) average variance extracted (AVE) above 0.5 ; and (3) composite reliability (CR) above 0.7 . The evaluation standard for discriminant validity is the square root of AVE for one dimension greater than the correlation coefficient with any other dimension(s). Results showed that standardized loadings ranges from 0.65 to 0.83 , most of which exceeded 0.70 threshold value. As Table 1 indicates, all three criteria for convergent validity were met, and correlation coefficients were all less than the square root of the AVE, suggesting that each dimension in this study had good discriminant validity.

TABLE I. MEASUREMENT VARIABLE RELIABILITY AND VALIDITY ANALYSIS

\begin{tabular}{|c|c|c|c|c|c|c|c|c|c|c|}
\hline & 1 & 2 & 3 & 4 & 5 & 6 & 7 & 8 & 9 & 10 \\
\hline 1.Career preparation & .814 & & & & & & & & & \\
\hline 2.Traditional goals & $.776^{* *}$ & .807 & & & & & & & & \\
\hline 3. Time management & $.541^{* *}$ & $.624^{* *}$ & .798 & & & & & & & \\
\hline 4.satisfaction & $.587^{* *}$ & $.656^{* *}$ & $.732^{* *}$ & .775 & & & & & & \\
\hline 5.Explorative teaching & $.673^{* *}$ & $.730^{* *}$ & $.580^{* *}$ & $.624^{* *}$ & .808 & & & & & \\
\hline 6.Advanced Learning & $.451^{* *}$ & $.465^{* *}$ & $.393^{* *}$ & $.435^{* *}$ & $.541^{* *}$ & .817 & & & & \\
\hline 7.Integrated learning & $.453^{* *}$ & $.482^{* *}$ & $.462^{* *}$ & $.524^{* *}$ & $.546^{* *}$ & $.694^{* *}$ & .676 & & & \\
\hline 8. Reflective learning & $.371^{* *}$ & $.380^{* *}$ & $.292^{* *}$ & $.336^{* *}$ & $.446^{* *}$ & $.580^{* *}$ & $.604^{* *}$ & .787 & & \\
\hline 9.cognitive gains & $.601^{* *}$ & $.634^{* *}$ & $.562^{* *}$ & $.611^{* *}$ & $.669^{* *}$ & $.655^{* *}$ & $.657^{* *}$ & $.539^{* *}$ & .636 & \\
\hline 10.non-cognitive gains & $.522^{* *}$ & $.538^{* *}$ & $.488^{* *}$ & $.533^{* *}$ & $.587^{* *}$ & $.557^{* *}$ & $.544^{* *}$ & $.522^{* *}$ & $.667^{* *}$ & .659 \\
\hline Means & 4.81 & 4.81 & 4.58 & 4.54 & 4.91 & 5.06 & 4.68 & 5.17 & 4.85 & 5.04 \\
\hline SD & 1.06 & 0.98 & 1.13 & 1.05 & 0.90 & 0.92 & 0.91 & 1.00 & 0.82 & 0.88 \\
\hline Crobach's $\alpha$ & .800 & .874 & .791 & .750 & .935 & .887 & .792 & .765 & .862 & .844 \\
\hline AVE & .662 & .651 & .637 & .601 & .652 & .668 & .457 & .619 & .405 & .434 \\
\hline CR & .797 & .881 & .778 & .751 & .937 & .889 & .802 & .764 & .857 & .821 \\
\hline
\end{tabular}




\section{B. Examination of Hypotheses}

This study adopted SEM to test hypotheses. The path coefficient of deep approach to learn in exploitative teaching is 0.405 ( $p<0.001)$. Hypothesis H1 was supported, in line with the views of other scholars, showing that students feel that the higher the level of teachers' exploitative-oriented teaching model, the higher the chance for students to invest in deep approach to learn. The path coefficient of deep approach to learn for explorative teaching was $0.314(\mathrm{p}<0.001)$. Hypothesis $\mathrm{H} 2$ was supported. It shows that students feel that the higher the teacher's use of explorative-based learning model is, the higher the student's ability to develop a deep approach to learn model. In addition, the path coefficients of cognitive and non-cognitive outcomes for teacher-exploitative teaching were $0.498(\mathrm{p}<0.001)$ and $0.637(\mathrm{p}<0.001)$, respectively. It show that the higher the degree of teaching by the teacher in exploitative teaching, will improve the student learning outcomes, the hypothesis $\mathrm{H} 3$ is supported. However, the path coefficients of cognitive exploration benefit and non-cognitive benefit for teacher explorative teaching were $-0.068(\mathrm{p}<0.05)$ and $-0.131(\mathrm{p}<0.01)$ respectively. It shows that teachers' continuous use of explorative teaching methods will negatively reduce the outcomes of student learning. This result is contrary to the assumptions deduced in this study. Hypothesis $\mathrm{H} 4 \mathrm{did}$ not receive support. In addition, the path coefficients of the students' deep approach to learn model for cognitive and non-cognitive benefits were $0.555 \quad(p<0.001)$ and $0.408 \quad(p<0.001)$, respectively. This means that the shape and construction of the deep approach to learn model can positively improve student learning outcomes, and H5 are also supported.

\section{CONCLUSION}

This study takes higher education as the main axis and uses SEM to explore the relationship between teachers' teaching methods, students' learning patterns, and student learning outcomes. There are two reasons for this study to explore the subject of this research structure, which are considered at the theoretical level and the practical level; on the theoretical level, in the past research on deep approach to learn constructs, the roles of teachers are rarely included in the common discussion, and the learning process of "stimulus $\rightarrow$ cognition $\rightarrow$ results" in cognitive learning theory is exploitative to this research framework, deep approach to learn constructs play an important role in teacher teaching and student learning outcomes. On the practical level, what most people criticize is that learning is useless, the reason for this is that students' learning aspirations are poor, which results in low learning outcomes. However, the reason for the lack of motivation for learning is diversified. Therefore, how to attract students to in-depth learning through effective teaching methods and demonstrate high learning outcomes is the focus of this study.

\section{REFERENCES}

[1] Biggs, J., \& Tang, C. (2011). Teaching for quality learning at university: What the student does: McGraw-Hill Education (UK).

[2] Campbell, C. M., \& Cabrera, A. F. (2014). Making the Mark: Are Grades and Deep approach to learn Related? Research in Higher Education, 55(5), 494-507.
[3] Choi, B. K., \& Rhee, B. S. (2014). The influences of student engagement, institutional mission, and cooperative learning climate on the generic competency development of Korean undergraduate students. Higher Education, 67(1), 1-18.

[4] Corbett, A. C. (2005). Experiential learning within the process of opportunity identification and exploitation. Entrepreneurship Theory and Practice, 29(4), 473-491. 